DOI: https://doi.org/10.24297/jaa.v10i0.8252

\title{
Effect of Micronutrients on The Two Qatari Date Palm Cultivars Shishi and Lulu Through in Vitro Technic
}

Sara Aqeel and Rehab A. Sidky

Agriculture Research Department, Ministry of Municipality and Environment. Qatar

sidky1234rehab@hotmail.com

\begin{abstract}
Plant tissue responds to nutrient media due to the plant cultivars genetic diversity. The objective of this research is to determine the effects of micronutrients on date palm growth and which of these micronutrients are critical for improving growth combined with Paclobutrazol or without on in vitro of elongation stage. In vitro growth of two cultivars were determined by varying five treatments that included minor salts (EDTA-chelated iron, $\mathrm{CuSO}_{4}$ ) alone or combined with Paclobutrazol. The effects of these five treatments on plantlet length, trunk thickness, rooting number and Chlorophyll A, B was investigated. The results obtained after three months showed that, increasing copper sulphate on MS elongation media combined with Paclobutrazol was more effective for increasing the trunk thickness as well as rooting number compared with normal MS level. While poor response was found when Fe was increased in the chelated form of Fe-EDTA on MS elongation media. For cultivars, Shishi gave the highest plantlets length as well as root number. The maximum content of chlorophylls $A$ and $B$ were observed when copper sulphate was increased on MS elongation media with cultivar Lulu. The survival rate after 3 months was related to the medium used during the elongation phase, the survival of plantlets reached to $98.66 \%$ with cultivar lulu at the acclimatization stage.
\end{abstract}

Key words: In Vitro, Elongation Stage, Paclobutrazol, Copper Sulphate, Iron. Date Palm, Cultivars, Biodiversity.

Abbreviations: PBZ: Paclobutrazol; Kinetin: Kin; Naphthalene acetic acid: NAA

\section{Introduction}

The date palm (Phoenix dactylifera) is the dominant component upon which the sustainable and socio-economic structures of the oasis ecosystem are based; a fruit tree with unique nutritional, biochemical and biophysical characteristics, a rich source of aesthetic and cultural values. Date palm is the only indigenous wild desert plant definitely domestic in its native harsh environment Jaradat, 2011[1]. As the world's food demand is increasing day by day due to the population growth and climate changes, we must develop new technology to promote this palm tree for future requirements. In January (2011), the UK report Global Food and Farming Futures stressed that investment in new technologies would be vital for the world to be able to feed themselves by 2050 .

The life cycle of palm dates is long, so it is difficult to improve, furthermore, to identify sex in the early stages of growth Moursy and Saker, 1996 [2] AlKhateeb and Alturki 2014 [3] mentioned that the propagation of date palms through tissue culture is useful than traditional method. Since Date palm is heterozygous, the propagation of seeds produces off-type plants, also propagation by offshoots is limited, and mortality is usually high. Mazri and Meziani 2015 [4] reported that there are two pathways for large-scale propagation of date palm, somatic embryogenesis and organogenesis.

Mineral salts have a role in all stages of the plant Leifert et al. 1995[5]; Ramage and Williams 2002, [6]. For growth, the plant needs 17 metal elements in specific concentrations Marschner 1995[7]. Furthermore, the absorption of ions from the medium to the plant tissues is limiting effects imposed by absorption of the ions in the field by root Williams 1993 [8]. Although the shoots response to absorption of mineral nutrients is complex but still Murashige and Skoog 1962 [9]. medium is the optimal medium. Metals like cobalt, iron, manganese, 
copper and zinc are essential for plant life but are required in a very small or trace amounts and become toxic at higher concentrations Hussein et al, 2010[ [10]. Copper is a microelement that is essential for normal growth and development of plants. Furthermore, iron is one of the basic microelements used in micro-propagation, since it is essential in many processes like chlorophyll and DNA synthesis Dunlap and Robacker 1988[11].

Plant hormones and plant growth regulators play important roles in improving transplanting rate Mohamed and Alsadon 2011[12]. Paclobutrazol (PBZ) is a member of the triazole family. Triazoles are considered as plant multi-protectants against various stresses Gilley and Fletcher, 1997[13]. PBZ affects the content of plant growth regulators by inhibiting gibberellin synthesis, reducing ethylene evolution, and increasing cytokinin level Kamountsis and Chronopoulou-Sereli, 1999[14]. also, Paclobutrazol was shown to improve transplanting efficiency of plants Fernandes et al. 2004[15].

This study were designed to determine the appropriate concentrations of the two micro salts (EDTA-chelated iron and copper sulphate) supplementation separate or with Paclobutrazol to the modified media for the elongation stage of date palm.

\section{Material and Methods}

This work was carried out in the Tissue Culture Lab. of Agriculture Research Department Doha, Qatar 20152016. The research have been implemented as follows:

\section{Plant Source and Culture Conditions}

Shoot tips of date palm (Phoenix dactylifera L.) were cultured as described by Aqeel and Elmeer, 2011[16]. One-year-old in vitro cultured plantlets "which derived from direct somatic embryogenesis" with two expanded leaves and an adequate root system (2 roots), $(5 \mathrm{~cm})$ long shoots of the date palm cultivar "Shishi" and "Lulu" were used for this experiment. Plantlets were cultured in Murashige and Skoog, 1962[9] supplemented with composition in (Table 1.) with five treatments for elongation medium. Plant length, trunk thickness, rooting number and Chlorophyll A and B of different explants were recorded after three sub-culture 4weeks intervals.

The cultures were incubated under a 16-hour light intensity of 4000 lux with a temperature of $25 \pm 2{ }^{\circ} \mathrm{C}$. Each treatment consisted of nine replicates of one plant in a test tube for evaluation the parameters after three subcultures (12 weeks). The experiment was repeated twice.

Table 1. Nutrient Media Composition Used for Elongation Stage

\begin{tabular}{|l|l|l|l|l|l|}
\hline $\begin{array}{l}\text { Medium } \\
\text { composition } \\
\left(\mathbf{m g ~ ~ ^ { - 1 }} \text { ) }\right.\end{array}$ & $\mathbf{M}_{\mathbf{1}}$ & $\mathbf{M}_{\mathbf{2}}$ & $\mathbf{M}_{\mathbf{3}}$ & $\mathbf{M}_{\mathbf{4}}$ & $\mathbf{M}_{\mathbf{5}}$ \\
\hline MS salts & 3,300 & 3,300 & 3.300 & 3,300 & 3,300 \\
\hline MS vitamins & 1.00 & 1.00 & 1.00 & 1.00 & 1.00 \\
\hline Fe-EDTA & 65 & 130 & 130 & 65 & 65 \\
\hline Copper Sulphate & 0.025 & 0.025 & 0.025 & 0.5 & 0.5 \\
\hline Sucrose & 50,000 & 50,000 & 30,000 & 50,000 & 50.000 \\
\hline Myo-inositol & 100 & 100 & 100 & 100 & 100 \\
\hline
\end{tabular}




\begin{tabular}{|l|l|l|l|l|l|}
\hline ca-penthathanete & 3 & 3 & 3 & 3 & 3 \\
\hline $\mathrm{KH}_{2} \mathrm{PO} 4$ & 170 & 170 & 170 & 170 & 170 \\
\hline kinetin & 0.3 & 0.3 & 0.3 & 0.3 & 0.3 \\
\hline NAA & 1.00 & 1.00 & 1.00 & 1.00 & 1.00 \\
\hline PBZ & - & - & 0.5 & - & 0.5 \\
\hline Difco agar & 6,000 & 6,000 & 6.000 & 6,000 & 6.000 \\
\hline
\end{tabular}

\section{Estimate the Amount of Chlorophyll in the Leaves of Date Palm Shishi and Lulu cvs.}

The chlorophyll (A and B) was determined as described by Costache et al., 2012 [17].

One gram of leaflets date palm tissue was put into test tube having $95 \%$ alcohol. The tissues were kept in the refrigerator all night, and then was centrifuged at $2500 \mathrm{rpm}$ for $10 \mathrm{~min}$. The supernatant was separated in another test tube. The maximum absorbance at 662 (chlorophyll A) and at 646 (chlorophyll B) was calculated using spectrophotometer.

\section{Plant Acclimatization}

Healthy Date palm plantlets about 10-14 cm in length, having 2-3 leaves and roots not less than 3-4 in number were selected for ex vitro transplantation in the green house. The plantlets were taken out from the test tubes and wash under running tap water to remove adhering agar, and then soaked for15 min in a solution of $2 \mathrm{~g} / \mathrm{L}$ systemic fungicide (Ridomil). Plantlets were shifted to $18 \mathrm{~cm}$ plastic pots filled with peat-moss, vermiculite (2:1 $\mathrm{v} / \mathrm{v})$. The plantlets were watered after a month with fertilization $1 \mathrm{~g} / \mathrm{l} \mathrm{N}-\mathrm{P}-\mathrm{K}$ (17-17-17), remove plastic tunnel after the first leaf appeared. The plantlets survival rate was calculated after 3 months of acclimatization Sidky et al., 2017 [18].

Treatments were replicated three times, separation of means among treatments was determined using LSD test at 5\% according to Steel et al., (1997) [19].

\section{Results}

In this study, we tested the effect of increase micronutrients with growth retardants on the media of elongation stage. The results obtained after three sub-culture showed that plantlets gave the greatest response in different culture of media.

\section{Effect of Different Media Composition on The Plantlet Length}

During the elongation phase, the responses of various media was shown in Table 2 and Fig. 1. Plantlets did not only grow healthy in M4 medium but also gave the highest plantlets with greener leaves when increase of copper sulphate in elongation media compared with normal MS level. The optimal elongation medium for plant length was noticed on M4 followed by M5 (19.67and $17.92 \mathrm{~cm}$ respectively). While, increasing of Fe in the chelated form of Fe-EDTA did not show significant effect as control treatment in the plant length. There is no significant difference between two the cultivars in terms of plantlet length, cultivar shishi gave the highest plant length $(17.07 \mathrm{~cm})$ compared to lulu $(16.80 \mathrm{~cm})$. 
According to the result on the interaction effect of cultivars and treatments, there is a significant interaction effect between two cultivars and treatments. The optimal medium for plantlet length was observed M4 medium with lulu cultivar.

Table 2: Mean Comparison of Two Date Palm Cultivars In Response To Different Media Composition on The Plantlet Length $(\mathrm{Cm})$.

\begin{tabular}{|c|c|c|c|c|}
\hline \multirow{3}{*}{\multicolumn{2}{|c|}{ Treatments }} & \multicolumn{3}{|l|}{ Average } \\
\hline & & \multicolumn{3}{|c|}{ cultivars } \\
\hline & & ShiShi & LuLu & Main (B) \\
\hline \multicolumn{2}{|l|}{ M1 } & 16.00 & 16.00 & 16.00 \\
\hline \multicolumn{2}{|l|}{ M2 } & 17.50 & 14.67 & 16.08 \\
\hline \multicolumn{2}{|l|}{ M3 } & 15.83 & 14.17 & 15.00 \\
\hline \multicolumn{2}{|l|}{ M4 } & 19.33 & 20.00 & 19.67 \\
\hline \multicolumn{2}{|l|}{ M5 } & 16.67 & 19.17 & 17.92 \\
\hline \multicolumn{2}{|l|}{ Main (A) } & 17.07 & 16.80 & \\
\hline L.S.D & $A=2.51$ & $B=1.59$ & \multicolumn{2}{|c|}{$A * B=3.55$} \\
\hline
\end{tabular}

Fig. 1 Effect of different media composition on the plantlet's length of date palm cultivars.

\section{Effect of different media composition on the trunk thickness}

According to the results obtained in Table 3 and Fig. 2, increase copper sulphate combined with PBZ on elongation medium positively influenced trunk thickness, trunk thickness significantly increases and strongly $(7.76 \mathrm{~mm})$. Concurrently combination Fe with PBZ show better response in trunk thickness than Fe-EDTA alone or control with significant difference.

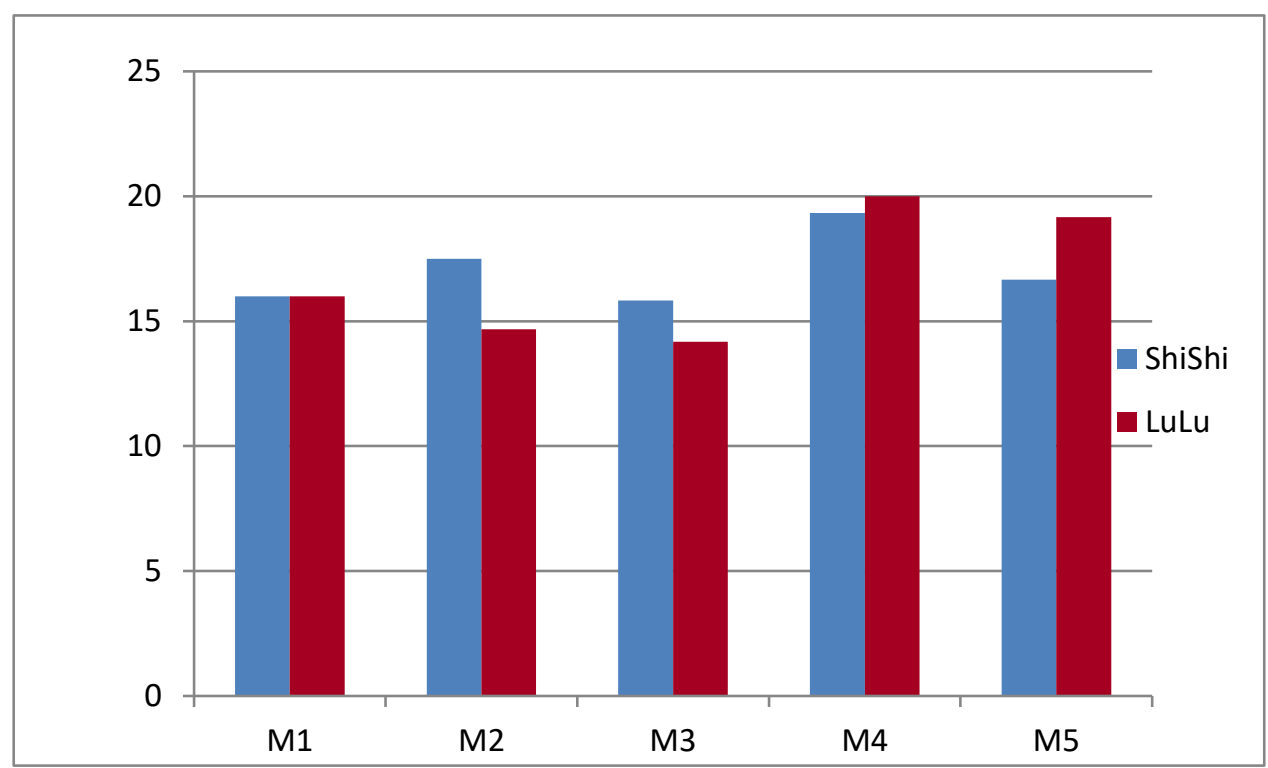


Moreover, it seemed that in Fig. 2 cultivar lulu gave the significant increase in trunk thickness $(6.98 \mathrm{~mm})$ than shishi cultivar $(5.39 \mathrm{~mm})$.

Data in Table 3 shows the interaction between cultivar and treatments was significant effect on trunk thickens, cultivar lulu gave the strongly trunk thickness with M5 medium $(8.67 \mathrm{~mm})$ followed by M4 medium (7.02 $\mathrm{mm}$ ) compared with other culture media.

Table 3: Mean Comparison of Two Date Palm Cultivars In Response To Different Media Composition on The Trunk Thickness (Mm).

\begin{tabular}{|c|c|c|c|}
\hline \multirow{3}{*}{ Treatments } & \multicolumn{3}{|l|}{ Average } \\
\hline & \multicolumn{3}{|l|}{ Cultivars } \\
\hline & ShiShi & LuLu & Main (B) \\
\hline M1 & 4.24 & 6.33 & 5.28 \\
\hline M2 & 5.31 & 6.32 & 5.81 \\
\hline M3 & 5.18 & 6.57 & 5.87 \\
\hline M4 & 5.38 & 7.02 & 6.20 \\
\hline M5 & 6.85 & 8.67 & 7.76 \\
\hline Main (A) & 5.39 & 6.98 & \\
\hline L.S.D & $A=1.197$ & $B=0.757$ & $A * B=1.693$ \\
\hline
\end{tabular}

Regarding to the results obtained in Table 4, there was significant difference between cultivar and treatments in root number, the highest number of root was obtained in cultivar shishi with M5 medium an average of 13.50 root/ plantlets.

Table 4: Mean Comparison of Two Date Palm Cultivars in Response to Different Media Composition on Rooting Number.

\begin{tabular}{|l|l|l|l|}
\hline \multirow{2}{*}{ Treatments } & \multicolumn{2}{|l|}{ Average } \\
\cline { 2 - 4 } & \multicolumn{2}{|l|}{ Cultivars } & \multicolumn{2}{|l|}{} \\
\cline { 2 - 4 } & \multicolumn{2}{|l|}{ ShiShi } & \multicolumn{2}{|l|}{ LuLu } & \multicolumn{2}{|l|}{ Main (B) } \\
\hline M 1 & 6.33 & 5.83 & $\mathbf{6 . 0 8}$ \\
\hline M 2 & 4.83 & 6.17 & $\mathbf{5 . 5 0}$ \\
\hline M 3 & & 6.33 & $\mathbf{5 . 6 7}$ \\
\hline
\end{tabular}




\begin{tabular}{|l|l|l|l|}
\hline M 4 & 5.33 & 6.17 & $\mathbf{5 . 7 5}$ \\
\hline M 5 & 13.50 & 8.50 & $\mathbf{1 1 . 0 0}$ \\
\hline Main (A) & $\mathbf{7 . 0 0}$ & $\mathbf{6 . 6 0}$ & \\
\hline L.S.D & $\mathbf{A}=\mathbf{0 . 6 2}$ & $\mathbf{B}=\mathbf{0 . 9 9}$ & $\mathbf{A}$ *B $=\mathbf{1 . 3 9}$ \\
\hline
\end{tabular}

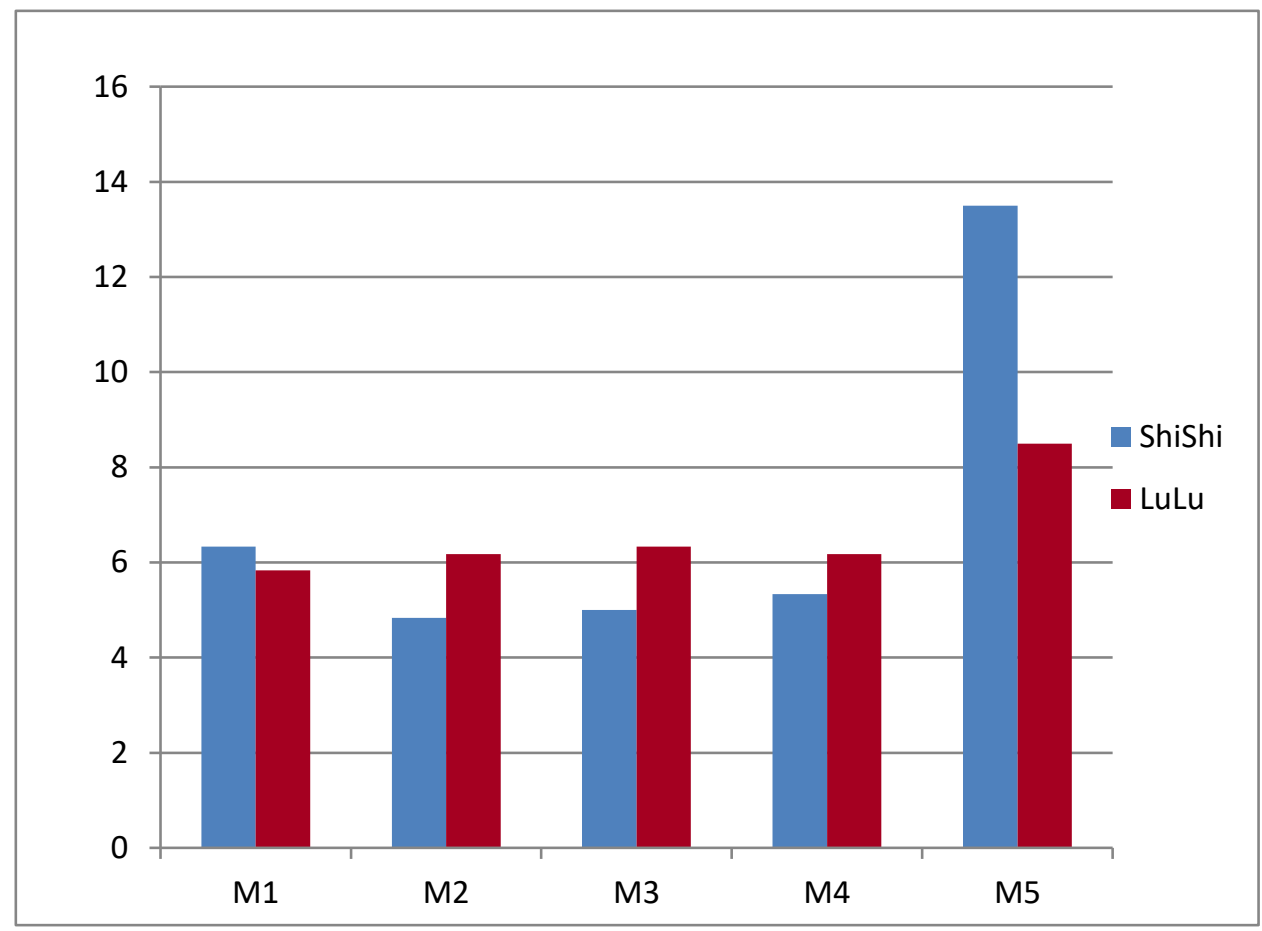

Fig. 3 Effect of different media composition on the rooting number of date palm cultivars.

\section{Effect of different media composition on the leaves chlorophyll A content}

\begin{tabular}{|l|l|l|l|}
\hline \multirow{2}{*}{ Treatments } & \multicolumn{2}{|l|}{ Average } \\
\cline { 2 - 4 } & \multicolumn{2}{l|}{ cultivars } & \multicolumn{2}{l|}{} \\
\cline { 2 - 4 } & ShiShi & LuLu & Main (B) \\
\hline M 1 & 13.39 & 22.23 & 17.81 \\
\hline M 2 & 46.54 & 32.54 & 39.54 \\
\hline M 3 & 26.71 & 34.92 & 30.81 \\
\hline M 4 & 37.51 & 96.52 & 67.01 \\
\hline M 5 & 35.65 & 56.08 & 45.86 \\
\hline
\end{tabular}




\begin{tabular}{|l|l|l|l|}
\hline Main (A) & 31.96 & 48.46 & \\
\hline L.S.D & $\mathrm{A}=0.95$ & $\mathrm{~B}=1.49$ & $\mathrm{~A}^{*} \mathrm{~B}=2.11$ \\
\hline
\end{tabular}

Differences between cultivars were observed, cultivar lulu gave the maximum content of Chlorophyll A (48.46 $\mathrm{mg} / 100 \mathrm{~g})$ than cultivar shishi $(31.96 \mathrm{mg} / 100 \mathrm{~g})$. Data in Fig. 4 show that the interaction between cultivar and treatments were significant, cultivar lulu gave the maximum content of Chlorophyll A when plantlets cultured on M4 medium ( $96.52 \mathrm{mg} / 100 \mathrm{~g}$ ), and followed by M5 medium (56.08 mg/100 g) compared with control or any other media.

Table 5 . Mean Comparison of Two Date Palm Cultivars in Response To Different Media Composition on Chlorophyll A Content.

\begin{tabular}{|c|l|l|l|}
\hline \multirow{2}{*}{ Treatments } & \multicolumn{2}{|l|}{ Average } \\
\cline { 2 - 4 } & \multicolumn{2}{|l|}{ Cultivars } & \multicolumn{2}{l|}{ LuLu } & Main (B) \\
\cline { 2 - 4 } & ShiShi & 22.23 & 17.81 \\
\hline M 1 & 13.39 & 32.54 & 39.54 \\
\hline M 2 & 46.54 & 34.92 & 30.81 \\
\hline M 3 & 26.71 & 96.52 & 67.01 \\
\hline M 4 & 37.51 & 56.08 & 45.86 \\
\hline M 5 & 35.65 & $\mathbf{4 8 . 4 6}$ & \\
\hline Main (A) & $\mathbf{3 1 . 9 6}$ & B $=\mathbf{1 . 4 9}$ & A*B $=\mathbf{2 . 1 1}$ \\
\hline L.S.D & A $=\mathbf{0 . 9 5}$ &
\end{tabular}




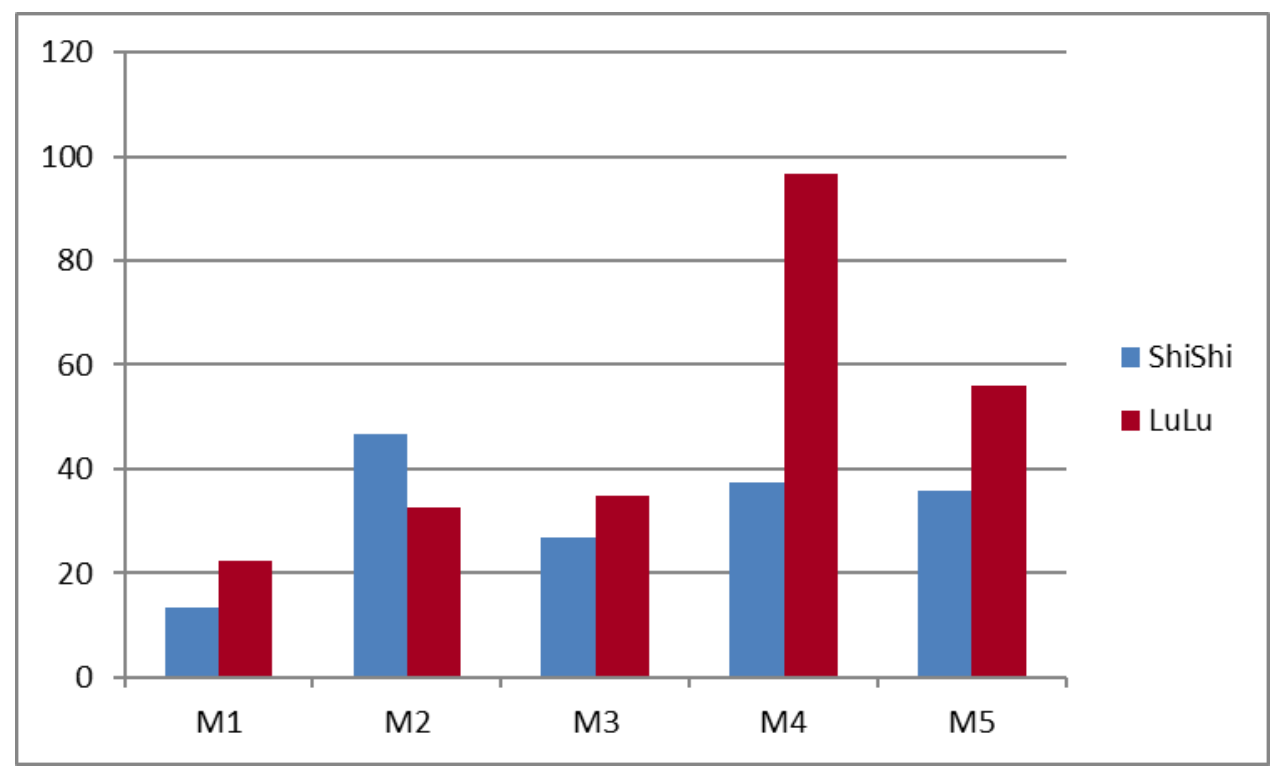

Fig. 4 Effect of Different Media Composition on The Chlorophyll A Content of Date Palm Cultivars.

\section{Effect of different media composition on the leaves chlorophyll B content}

It seemed that a similar effect of Chlorophyll B content observed in Table 6 and Fig. 5, the highest content of Chlorophyll B was observed when increase copper sulphate on elongation media. M4 medium increased Chlorophyll B content $(14.01 \mathrm{mg} / 100 \mathrm{~g})$ followed by M5 and M2 medium $(10.66,10.90 \mathrm{mg} / 100 \mathrm{~g}$, respectively). Whereas the poor content in control medium $(4.39 \mathrm{mg} / 100 \mathrm{~g})$.

Table 6: Effect of Different Media Composition on The Chlorophyll B Content After Three Sub- Culture of Date Palm Cultivars.

\begin{tabular}{|l|l|l|l|}
\hline \multirow{2}{*}{ Treatments } & \multicolumn{2}{|l|}{ Average } \\
\cline { 2 - 4 } & \multicolumn{2}{|l|}{ Cultivars } & \multicolumn{2}{l|}{} \\
\cline { 2 - 4 } & \multicolumn{2}{|l|}{ ShiShi } & \multicolumn{2}{l|}{ Lulu } \\
\hline M 1 & 4.39 & 5.23 & $\mathbf{4 . 3 9}$ \\
\hline M 2 & 12.59 & 9.21 & $\mathbf{1 0 . 9 0}$ \\
\hline M 3 & 6.61 & 8.09 & $\mathbf{7 . 3 5}$ \\
\hline M 4 & 3.82 & 24.20 & $\mathbf{1 4 . 0 1}$ \\
\hline M 5 & 6.55 & 14.76 & $\mathbf{1 0 . 6 6}$ \\
\hline Main A & $\mathbf{6 . 7 9}$ & $\mathbf{1 2 . 3 0}$ & \\
\hline L.S.D & $\mathbf{A}=\mathbf{0 . 3 6}$ & B =0.57 & A*B =0.799 \\
\hline
\end{tabular}


Data showed a significant difference between cultivars, cultivar lulu gave the highest content of Chlorophyll B (12.30 mg/100 g).As well as, the maximum content of Chlorophyll B was obtained when plantlets cultured on M4 medium with cultivar lulu $(24.20 \mathrm{mg} / 100 \mathrm{~g})$.

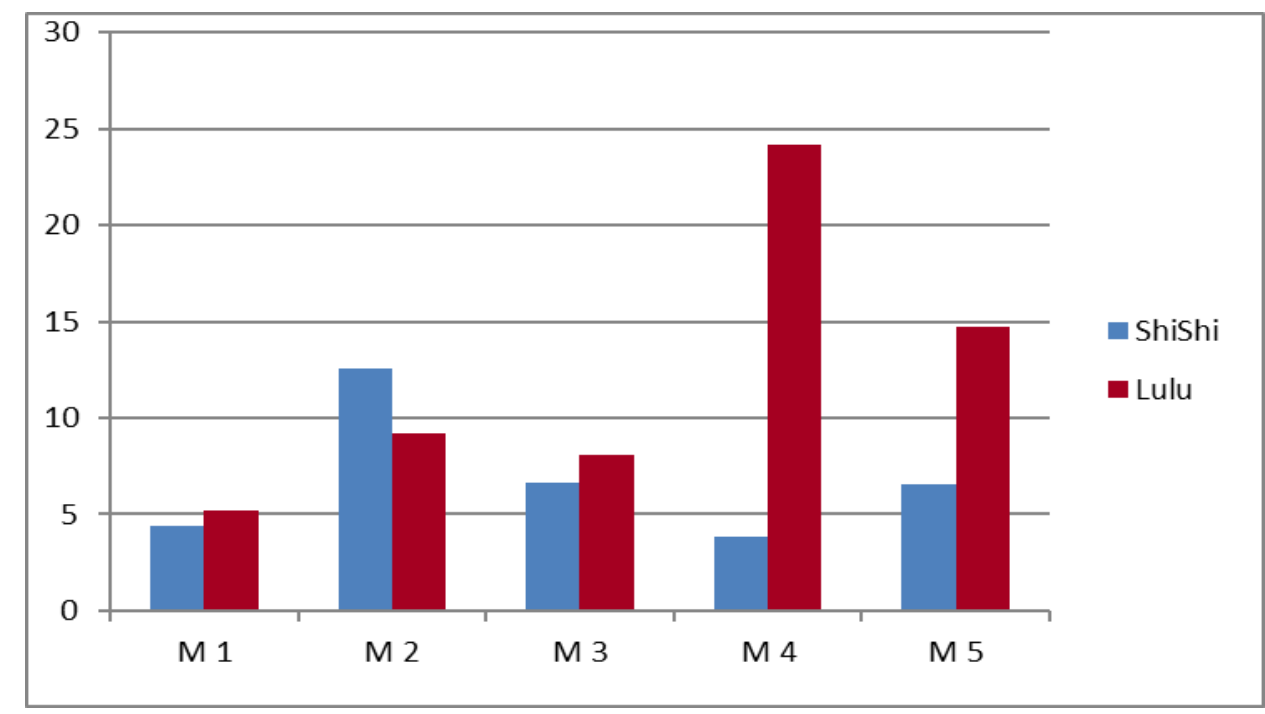

Fig. 5 Effect Of Different Media Composition on The Chlorophyll B Content of Date Palm Cultivars

In all Tables, Data indicate mean A: Cultivars

Data indicate mean B: Treatments Data indicate mean $A * B$ : interaction

Thus, increased copper sulphate on MS elongation media (M4) increased the biosynthesis of chlorophyll A, B. and plantlets have good photosynthetic capacity. While addition iron in the form of Fe-EDTA (M2) was obtained less content of chlorophyll A biosynthesis.

\section{Acclimatization}

Our findings showed after three months of transplantation in greenhouse (Fig. 6), plantlets were cultured on (M5) medium increased survival rate at acclimatization stage. The highest survival rate was $98.66 \%$ with cultivar lulu.

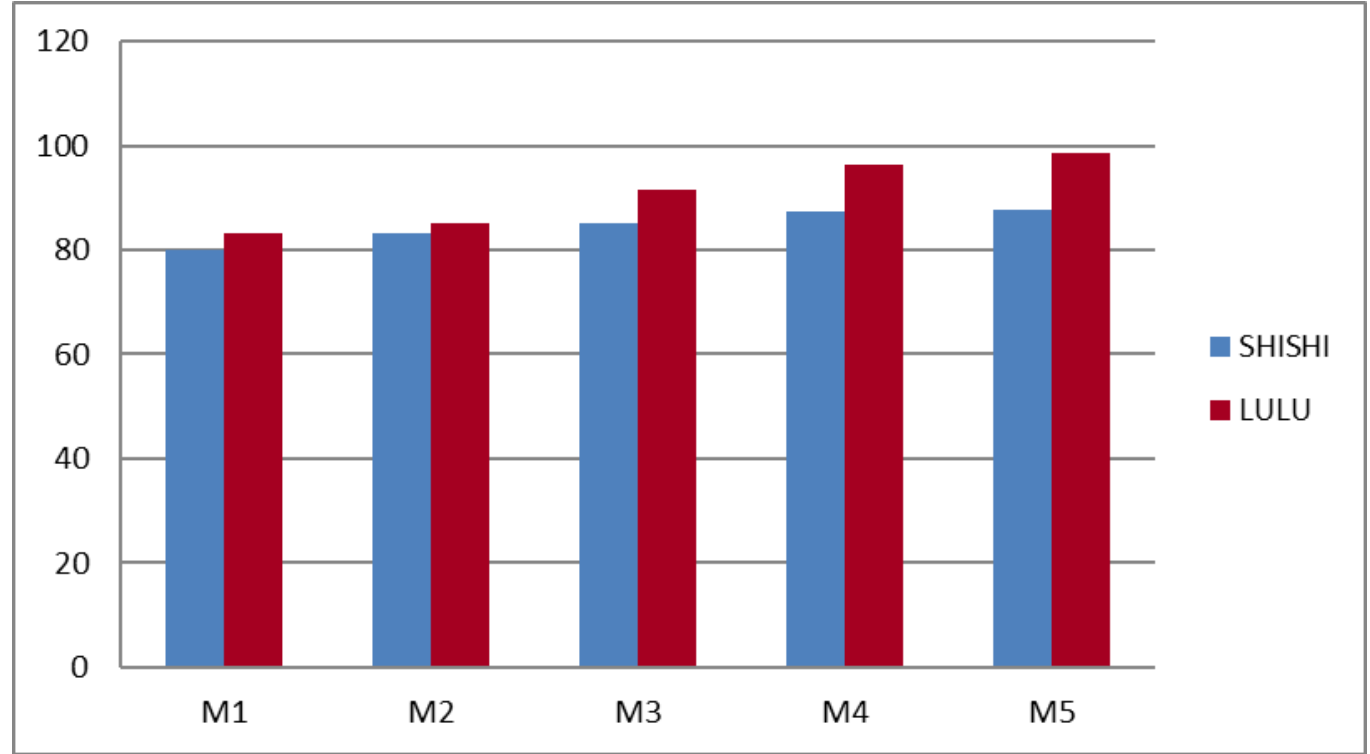




\section{Fig. 6 Effect of different media composition on survival rate of plantlets after 3 months from acclimatization of date palm cultivars.}

\section{DISCUSSION}

Murashige and Skoog, 1962 [9] salts had a role in identifying minerals reactions in the nutrient medium and absorption it (Reed et al., 2013) [20]. In this study, experiment was designed in order to modify elongation media by increase some minor salts for two Qatari date palm cultivars.

The growth in term of plantlets length, trunk thickness, rooting number and Chlorophyll A, B of date palm cultures are strongly influenced by increasing copper sulphate.

For optimum success, our data found that on elongation media (M5) increasing copper sulphate combined with Paclobutrazol gave the best plantlets in terms of trunk thickness and root formation compared with normal MS level. Furthermore, it was found that the highest plantlets with greener leaves occurred when increasing of copper sulphate on elongation media. Many authors point to a positive influence of increase copper ions concentrations. Nas (2004) [21] suggested that higher levels of $\mathrm{Cu}$ (up to $5.1 \mathrm{mg} \mathrm{CuSO} 4 \times 5 \mathrm{H}_{2} \mathrm{O} \mathrm{dm}-3$ ) in hazelnut (Corylus spp.) explants lead to undifferentiated cell from (callus production) derived to cell differentiation (shoot and bud formation), this combination enhance the morphogenetic potential of explants. Joshi and Kothari (2007) [22] reported that the induction of shoot buds was happened by increasing concentration of copper in medium as well as cotyledon explants of Capsicum annuum $L$ were more developing. The highest number of shoots and longer shoots were obtained from one explant on medium with $4.8 \mathrm{mg}$ CuSO4 $\mathrm{dm}^{-3}$. Prażak and Molas (2015) [23] found that Concentration of $\mathrm{Cu}$ (mostly $0.625 \mathrm{mg} \mathrm{CuSO}_{4} \times 5 \mathrm{H}_{2} \mathrm{O}$ $\mathrm{dm}-3$ ) encourage the elongation shoots and roots of orchid. Rafail et al., (2012) [24] reported that the highest number of branches and leaves per explant for apple and pear was obtained in a treatment with $0.05 \mathrm{mg} \mathrm{dm}^{-3}$ of copper in culture medium. Dahleen (1995) [25] investigate the effect of different level of CusO $\mathrm{C}_{4}$ on callus culture of two barley cultivars, medium containing 50 $\mu \mathrm{M}$ copper gave 17 plants per embryo while, normal MS level gave only 5 plants per embryo.

The results of the current study are on the same parallel with those published by Sidky (2007) [26] who indicated that, PBZ improved the trunk thickness of plantlets date palm cv. Samani. Paclobutrazol caused the production of thicker roots in respect to controls (IBA). Moreover, it increased the production of lateral roots, especially in cherry, most plantlets rooted on paclobutrazol-enriched media overcame the acclimatization phase Marino, 1988; Browning et al. (1992) $[27,28]$ investigated the effect of PBZ on the translocation of endogenous IAA in Doyenne du Comice pear cultivar. PBZ induced changes in growth and productivity of agronomical and horticultural crops had been described in some studies (Ghosh et al., 2010) [29].

Our findings suggest that, when Fe was increase on media $(M 2, M 3)$ in the form of Fe-EDTA poor response was recorded, although Fe-EDTA was found to be a suitable form of iron in the medium, perhaps this is due to existence cu in the media. This result is agreed with Ouzounidou et al. (1992) [30] who reported that, reduce absorption of elements such as $\mathrm{Ca}, \mathrm{Mg}, \mathrm{K}$ and Fe by increasing $\mathrm{Cu}$ concentration in nutrient medium. Molassiotis et al., (2003) [31] reported that when treated peach rootstock GF-677 explants with Fe EDTA (normal level of MS medium) no roots were generated.

It has become evident that micronutrients play important roles on the leaves chlorophylls content, the highest content of Chlorophylls were observed when increasing copper sulphate on elongation media. Same result was earlier reported by AL-Mayahi (2014) [32], in the presence of copper sulphate and Cobalt chloride" in MS media Chlorophyll A, B and total Chlorophyll were increasing. Vinod et al., 2012 [33], mentioned that, high concentration of $\mathrm{Cu}$ and $\mathrm{Zn}$ increase Chlorophyll contents.

Acclimatized is a very important step to complete propagation process of date palm plantlets, increasing concentrations of copper sulphate combined with Paclobutrazol increasing survival rate in acclimatization stage as has been manifested in data. Maximum survive ability was noticed for plants cultured in media that containing 
both copper sulphate and cobalt chloride at $0.5 \mu \mathrm{M}$ [31], Purnhauser and Gulai (1993) [34] mentioned that, increasing the content of copper in regeneration medium had an effect in increasing the survival rate at acclimatization.

\section{Conflicts of Interest}

There is no conflicting

\section{Funding Statement}

The research was funded by the researchers themselves

\section{Conclusions}

The concentration of $\mathrm{CuSO}_{4}$ in the standard MS medium is not optimal for elongation stage of date palm. Modified MS elongation medium by increase concentrations of copper sulphate than normal MS levels combined with Paclobutrazol had a positive effect of date palm cultivars. These increases of copper sulphate "Cuso 4 " enhance trunk thickness, roots regeneration and Chlorophylls content.

\section{References}

1. Jaradat, A.A. 2011. Biodiversity of Date Palm. Cover and Soil Sciences, [Ed.-], in Encyclopedia of Life Support Systems (EOLSS), Developed under the Auspices of the UNESCO, Eolss Publishers, Oxford, UK.

2. Moursy, H.A. and M.M. Saker 1996. Date palm problems and need for biotechnology. Fifth International Conference on Desert Development, Texas Tech University, August 12-17, 1996, USA.

3. AlKhateeb, A. A. and S. M. Alturki 2014. A comparison of liquid and semi-solid cultures on shoot multiplication and rooting of three date palm cultivars (Phoenix dactylifera L.) in vitro. Adv. Environ. Biol., 8(16), 263-269.

4. Mazri, M. A. and R. Meziani 2015. Micropropagation of Date Palm: A Review. Cell Dev Biol 4: 160

5. Leifert, C., K.P. Murphy and P.J. Lumsden 1995. Mineral and carbohydrate nutrition of plant cell and tissue cultures. Crit Rev Plant Sci 14(2):83-109

6. Ramage, C.M and R.R. Williams 2002. Mineral nutrition and plant morphogenesis. In vitro Cell Dev Biol Plant 38:116-124

7. Marschner, H. 1995. Mineral nutrition of higher plants. Academic Press, New York, pp 1-5.

8. Williams, R.R. 1993. Mineral nutrition in vitro-a mechanistic approach. Aust J Bot 41:237-251

9. Murashige, T. and F. Skoog 1962. A revised medium for rapid growth and bioassays with tobacco tissue cultures. Physiol Plant 15:473-49.

10. Hussein, K., K.K. Sahadevan and N. Salim 2010. Bioaccumulation and release of mercury in Vigna mungo (L.) hepper seedlings. J. Stress Phys. Biochem., 6: 56-63.

11. Dunlap, J.R. and K.M. Robacker 1988. Nutrient salts promote light-induced degradation of indole-3acetic acid in tissue culture. Plant Physiology 88:379-382.

12. Mohamed, M.A.H. and A.A. Alsadon 2011. Effects of vessel type and growth regulators on micropropagation of Capsicum annuum. - Biol. Plant. 55: 370-374. 
13. Gilley, A. and R.A. Fletcher 1997. Relative efficacy of paclobutrazol, propiconazole and tetraconazole as stress protectants in wheat seedlings. Plant Growth Regulation 21: 169-175.

14. Kamountsis, A.P. and A.G. Chronopoulou-Sereli 1999. Paclobutrazol affects growth and flower bud production in gardenia under different light regimes. Hort. Sci. 34-4: 674-675.

15. Fernandes, J.A., L. Balenzategui, S. Banon, J.A. Franco 2004. Induction of drought tolerance by paclobutrazol and irrigation deficit in Phillyrea angustifolia during the nursery period. - Sci. Hort. 107: 277-283.

16. Aqeel, S. and K. Elmeer 2011. Effects of Casein Hydrolysates and Glutamine on Callus and Somatic Embryogenesis of Date Palm (Phoenix dactylifera L.). New York Science Journal, 4: 121-125.

17. Costache, M.A., G.H. Câmpeanu, G. Neaţă 2012. Studies concerning the extraction of chlorophyll and total carotenoids from vegetables. Romanian Biotechnological Letters, 17: 7702-7708.

18. Sidky, R.A., M. AL-Salahi and A. Al-Mahmoud 2017. Establishment of an efficient protocol for rooting and acclimatization of two Qatari date palm cultivars Shishi and Lulu. International Journal Advanced Biological Research, 7: 1-5.

19. Steel, R.G., J.H. Torrie and D. Dickey 1997. Principles and Procedures of Statistics: A Biometrical Approach. The McGraw-Hill Co Inc, New York.

20. Reed, B.M., S. Wada, J. DeNoma, and R. P. Niedz 2013. Improving in vitro mineral nutrition for diverse pear germplasm. In vitro Cell.Dev. Biol 22.

21. Nas, M. N. 2004. The effects of elevated myo-inositol and copper on morphogenetic response of hazelnut (Corylus spp.) explants. KSU J. Sci. Engin., 7(1): 116-119.

22. Joshi, A. and S. L. Kothari 2007. High copper levels in the medium improves shoot bud differentiation and elongation from the cultured cotyledons of Capsicum annuum

23. Prażak R. and J. Molas 2015. Effect of copper concentration on micro-propagation and accumulation of some metals in the Dendrobium kingianum Bidwill Orchid. J. Elem.20(3): 693-703.

24. Rafail, S. T., H. D. Gharbia and N. Y. Atheel 2012. In vitro morphogenetic response of apple (Malusdomestica Borkh.) and pear (Pyrus communis L.) to the elevated levels of copper and myo-inositol. Acta Agrobot. 65(3): 43-48.

25. Dahleen, L.S. 1995. Improved plant regeneration from barley callus cultures by increased copper levels. Plant Cell Tiss. Org. Cult., 43: 267-269. DOI: 10.1007/BF00039954.

26. Sidky, R.A., Z.E. Zaid and A. El-Bana 2007. Optimized protocol for in vitro rooting of date palm (Phoenix dactylifera L.). Proc Fourth Int Symp on Date Palm, King Faisal University, Al Hassa, Saudi Arabia, pp 454467.

27. Marino, G. 1988. The effect of paclobutrazol on in vitro rooting, transplant establishment and growth of fruit plants. Plant Growth Regulation 7: 237-247

28. Browning, G., A. Kuden and P. Blanke 1992. Site of (2RS, 3RS) Paclobutrazol promotion of axillary flower initiation in Pear cv. Doyenne du Comice. J. Hort. Sci. 67 (1), 121-128.

29. Ghosh, A., J. Chikara, D.R. Chaudhary, A.R. Prakash, G. Boricha and A. Zala 2010. Paclobutrazol arrests vegetative growth and unveils unexpressed yield potential of Jatropha curca. J. Plant Growth Regul. 29, 307-315. 
30. Ouzounidou, G., E.P. Eleftheriou and S. Karataglis 1992. Ecological and ultrastructural effects ofcopper in Thlaspi ochroleucum (Cruciferae). Canad. J. Bot., 70: 947-957

31. Molassiotis, A.N., K.N. Dimassi, I.N. Therios and G.R. Diamantidis 2003. Fe-EDDHA promotes rooting of rootstock GF-677 (Prunus amygdalus P. persica) explants in vitro. Biol. Plant 47:141-144.

32. AL-Mayahi, A.M. 2014. Effect of copper sulphate and cobalt chloride on growth of the in vitro culture tissues for date palm (phoenix dactylifera l.) cv. Ashgar. American Journal of Agricultural and Biological Sciences 9 (1): 6-18.

33. Vinod, K., G. Awasthi and P.K. Chauhan 2012. Cu and Zn tolerance and responses of the Biochemical and Physiochemical system of Wheat. J. Stress Physiol

34. Purnhauser, L. and G. Gyulai 1993. Effect of copper on shoot and root regeneration in wheat, triticale, rape and tobacco tissue cultures. Plant Cell, Tiss. and Org. Cult. 35:131-139. 